\title{
Com influencia la temperatura en el creixement de les hortalisses en un hivernacle
}

\author{
Jesús Chivite Pérez \\ Escola Sant Josep - El Pi (L'Hospitalet de LI.). Equip de formadors/es del Cesire CDEC \\ jchivite@xtec.cat \\ Conxita Màrquez Bargalló \\ Departament de Didàctica de la Matemàtica i de les Ciències Experimentals de la UAB
}

Es presenten unes activitats experimentals sobre la influència de la temperatura en el creixement de les plantes i la germinació de les llavors dins i fora d'un hivernacle i com ho mesurem amb la consola de sensors Ecodad, realitzades per alumnes de quart de Primària. Les activitats es desenvolupen en un context que afavoreix l'ús de les Tecnologies de l'Aprenentatge i el Coneixement (TAC), incorporades a l'activitat de classe.

Paraules clau: TAC, sensors, temperatura, hivernacle, hort urbà, mesures, recollida i treball de dades

"Ens han regalat un petit hivernacle pel nostre hort urbà situat a una terrassa de l'escola. Com que volem aprendre coses noves sobre la nutrició de les plantes hem pensat que seria una bona idea utilitzar aquest hivernacle i la consola de sensors que ens va presentar el mestre per fer diferents experiències. De les activitats que hem fet ens centrarem sobretot en les relacionades amb la temperatura, encara que també hem fet mesures, recollida i treball de les dades de llum i so."

Alumnes de 4t. de l'Escola Joan Maragall

\section{La unitat didàctica "Com creixen les plantes de I'hort?"}

Les experiències que presentem s'han treballat en la Unitat Didàctica "Com creixen les plantes de l'hort", amb alumnes de 4t de primària, fent servir diferents recursos tecnològics: consola de sensors (fig. 2), ordinadors, pissarra digital interactiva, càmera fotogràfica... La unitat completa es pot consultar en aquesta adreça.

Alguns dels objectius de la UD són:

- Conèixer les parts de les plantes i les seves funcions en el procés de nutrició de la planta.

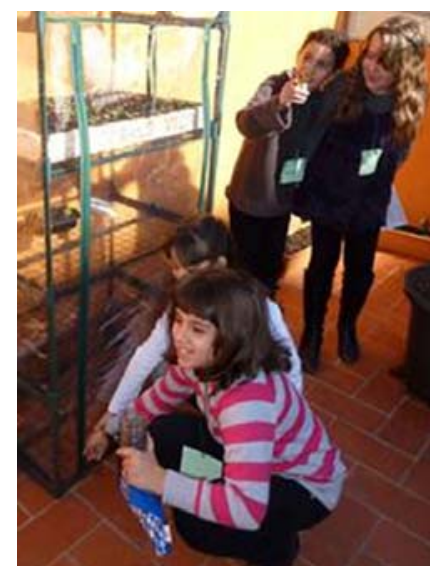

Figura 1. Alumnes de 4t. amb l'hivernacle durant el seu treball amb sensors. Escola Joan Maragall.

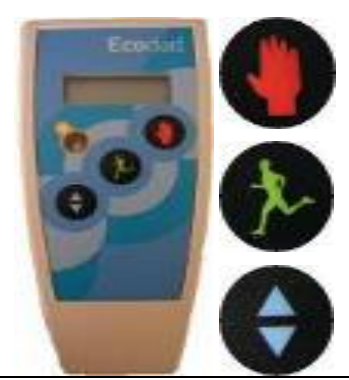

Figura 2. Consola de sensors Ecodad. 
- Identificar la diversitat de les plantes de l'hort en un entorn on hi ha interrelacions entre diferents éssers vius i l'ambient.

- Realitzar experiències senzilles on es controlen diferents variables com la temperatura, lluminositat, aire i humitat, per tal de comparar els seus efectes en el creixement de les plantes.

- Utilitzar les tecnologies, integrades en el treball de classe, de manera adient i acurada per mesurar i obtenir dades que després s'utilitzaran per analitzar, representar, interpretar i verificar aspectes rellevants i significatius de les plantes.

- Conèixer el conreu de la terra com una activitat humana que històricament ha estat molt lligada al barri i a la ciutat on viuen.

- Cooperar amb els companys i companyes amb tolerància, tot respectant la diversitat davant d'un projecte comú.

Forma part dels objectius d'aquesta UD el realitzar experiències per comparar la influència de diferents variables en els processos de germinació i creixement de les plantes utilitzant les TAC. Per assolir-los, cada grup de treball format per 5 alumnes, es va plantejar una pregunta on calia un control precís d'alguna de les variables implicades utilitzant la consola de sensors.

Per planificar i realitzar l'activitat es va acordar que cada grup seguiria la següent pauta de treball:

1) Pregunta d'investigació

2) Què pensem que passarà? (Hipòtesi)

3) Què tenim? (Materials necessaris)

4) Què fem? (Procediment)

5) Dibuix o foto del que fem (Procediment)

6) Què passa? (Observacions i recollida de dades)

7) Per què passa? (Justificació)

8) Hem verificat o no la nostra hipòtesi inicial?

9) Observacions

Podeu trobar els fulls de treball experimental sobre plantes dels alumnes al Bloc Taciències.

\section{Activitats prèvies}

Com a pas previ a la realització de les experiències es van fer dues sessions per presentar $\mathrm{i}$ manipular els recursos. Aquestes sessions es van fer col-lectivament $o$ en grups reduïts per familiaritzar els nens i les nenes amb l'ús dels sensors.

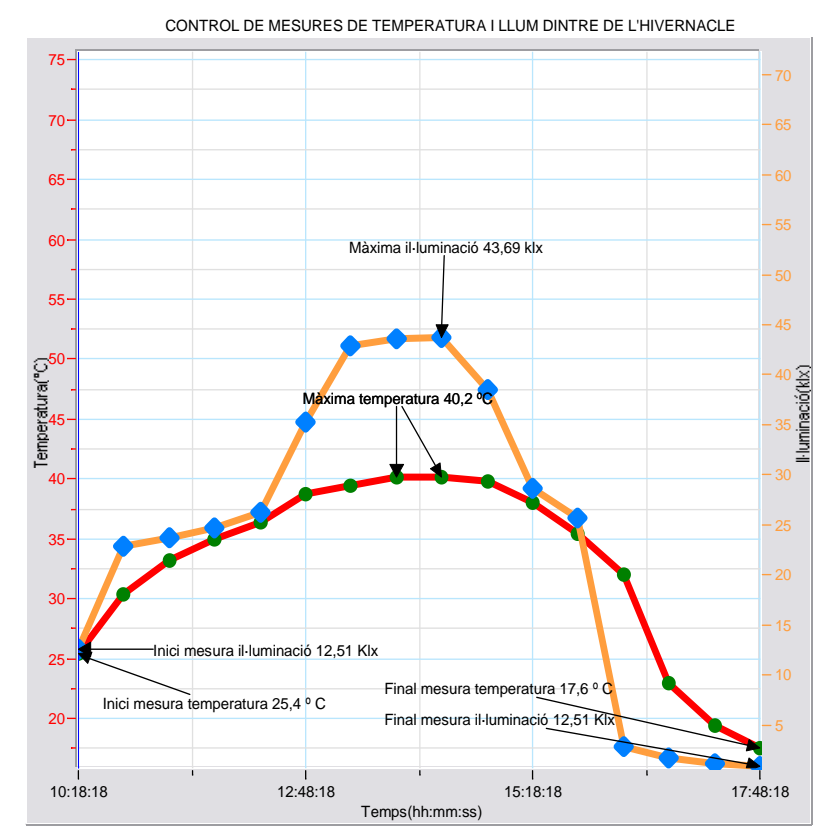

\begin{tabular}{ccc} 
Temps(hh:mm:ss) & Temperatura $\left({ }^{\circ} \mathbf{C}\right)$ & II·luminació(klx) \\
10:18:18 & 25,4 & 12,512 \\
10:48:18 & 30,4 & 22,874 \\
11:18:18 & 33,2 & 23,754 \\
11:48:18 & 35 & 24,731 \\
12:18:18 & 36,4 & 26,295 \\
12:48:18 & 38,8 & 35,288 \\
13:18:18 & 39,4 & 42,815 \\
13:48:18 & 40,2 & 43,597 \\
$14: 18: 18$ & 40,2 & 43,695 \\
14:48:18 & 39,8 & 38,514 \\
$15: 18: 18$ & 38 & 28,641 \\
15:48:18 & 35,4 & 25,61 \\
16:18:18 & 32 & 2,835 \\
16:48:18 & 23 & 1,76 \\
17:18:18 & 19,4 & 1,075 \\
17:48:18 & 17,6 & 0,782 \\
\hline
\end{tabular}

Figura 3. Gràfica i taula amb les dades corresponents a la temperatura i la lluminositat enregistrades dins de l'hivernacle. S'han utilitzat les dades generades entre les 10:18 i les 17:48 hores amb un interval de medició de 30 minuts.

\section{a) L'hivernacle}

Per tal de registrar si hi havia canvis de temperatura dins de l'hivernacle durant 24 hores es va programar una consola entre tota la classe, utilitzant la pissarra digital interactiva (PDI), perquè dins de l'hivernacle fes mesures cada 15 minuts. Es poden veure les dades i el gràfic resultants a lentrada del bloc de classe. 


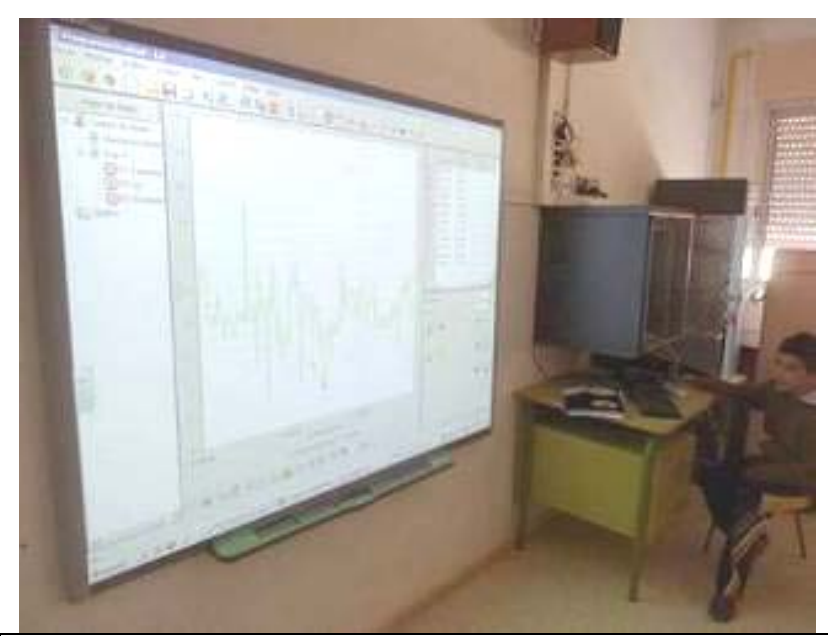

Figura 4. Alumne de 4t. manipulant amb la PDI una gràfica obtinguda amb els sensors.

\section{b) L'hort}

Posteriorment es van programar dues consoles perquè mesuressin la temperatura, la il.luminació $\mathrm{i}$ el so del nostre hort i de l'interior de l'escola (el corredor) durant tot el cap de setmana. L'objectiu era obtenir dades per després poder analitzar quines són les condicions més favorables per les hortalisses del nostre hort. Per fer-ho, els alumnes van programar l'Ecodad perquè capturés dades cada 30 minuts.

D'altra banda, per sintetitzar les activitats fetes amb la consola Ecodad, es va preparar un treball d'interpretació d'una gràfica i una taula amb dades reals de temperatura i llum que ells mateixos havien obtingut, i d'elaboració manual d'una gràfica sobre el paper amb unes dades donades. L'entrada d'aquest treball és al bloc de classe amb el nom de "Treball amb una gràfica de llum i temperatura".

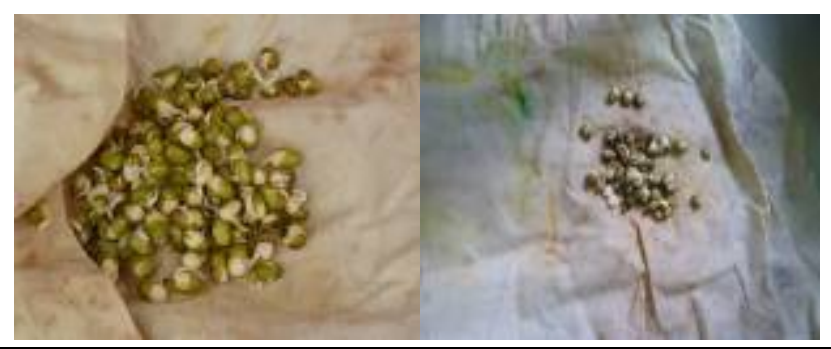

Figura 5. Llavors de soja germinades a l'hivernacle (esquerra) i a la classe (dreta).

Podem veure una gràfica i taula de temperatura i llum a la fig. 3 i un alumne treballant amb la classe a la fig. 4.

A l'entrada "Més medicions amb sensors" del bloc de la classe, es poden consultar les dades que vam obtenir i que ens van portar un temps de conversa i de feina per interpretar tant la taula de dades com les gràfiques. Als enllaços podreu veure la gràfica i dades tant de l'hort com del corredor.

\section{Experiències relacionades amb la variable temperatura}

Els objectius de les experiències relacionades amb la variable temperatura es concreten en les següents preguntes: "Com afecta la temperatura en el creixement de les plantes?" i "Com afecta la temperatura en la germinació de les llavors?". Al bloc de ciències de la classe de $4 \mathrm{t}$. es pot consultar un resum d'aquestes experiències fet pels alumnes en forma de presentació curta.

Les plantes que vam triar van ser unes bledes de l'hort que acabaven de néixer i les llavors utilitzades van ser unes de soja prèviament remullades. Els alumnes les van situar en dues condicions diferents, a dins i a fora de l'hivernacle, i van fer mesures i recollida de dades durant 9 dies.

Els alumnes comproven que hi ha una diferència de temperatura ambient entre l'hort $i$ l'hivernacle: les llavors de l'hivernacle eren a una temperatura superior (un dia vam arribar a tenir-hi $46{ }^{\circ} \mathrm{C}$ ) mentre que les de classe estaven a una temperatura d'uns $22-23^{\circ} \mathrm{C}$. Com es pot apreciar a la fig. 5, les llavors de soja de l'hivernacle es van desenvolupar més ràpid que les de fora gràcies a aquesta escalfor.

Per comprovar el creixement van mesurar tres plantetes de bledes a l'interior de l'hivernacle i tres plantetes a fora durant 9 dies (fig. 6).

Van calcular la mitjana de les mides i van poder comprovar que el creixement havia estat superior en les plantetes de dins de l'hivernacle (fig. 7).
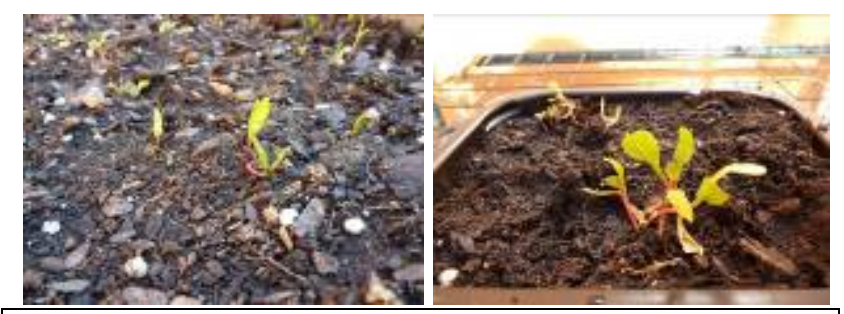

Figura 6. Plantetes de bleda amb l'escalfor de l'hivernacle (dreta) i a l'hort (esquerra).

I van concloure que una escalfor controlada afavoreix el creixement de les plantes. També van observar que cal ventilar l'hivernacle de tant en tant perquè sinó hi ha molta escalfor i condensació d'aigua i les plantes es podrien morir. 


\begin{tabular}{|c|r|l|r|}
\hline \multicolumn{2}{|c|}{ Exterior (taula de l'hort) } & \multicolumn{2}{l|}{ Interior (hivernacle) } \\
\hline Bleda 1 & $1,5 \mathrm{~cm}$ & Bleda 1 & $2,5 \mathrm{~cm}$ \\
\hline Bleda 2 & $2,0 \mathrm{~cm}$ & Bleda 2 & $2,0 \mathrm{~cm}$ \\
\hline Bleda 3 & $+1,5 \mathrm{~cm}$ & Bleda 3 & $+2,3 \mathrm{~cm}$ \\
\hline Total & $5,0 \mathrm{~cm}$ & Total & $6,8 \mathrm{~cm}$ \\
\hline $5,0 \mathrm{~cm} / 3=$ & $1,66 \mathrm{~cm}$ & $6,8 \mathrm{~cm} / 3=$ & $2,26 \mathrm{~cm}$ \\
\hline
\end{tabular}

Figura 7. Taula amb mesures de les bledes a l'exterior i a l'interior de l'hivernacle.

Una vegada realitzades totes les experiències. Tots els grups van fer una presentació que es va penjar al bloc de ciències de la classe i posteriorment, amb el suport de la PDI, van mostrar i explicar als seus companys i mestres el que havien realitzat. Van ser unes activitats molt enriquidores que van permetre als alumnes fer un treball interdisciplinar molt complet.

\section{Té sentit l'ús dels sensors?}

En acabar l'activitat es va demanar als alumnes que contestessin de forma individual un qüestionari de valoració de les diferents activitats fetes.

Van manifestar el seu interès davant de l'ús de sensors a la classe de ciències $i$, tot i que no va ser el que més els atreia i agradava, la seva valoració va ser força alta (sobre un 85-90 \% de satisfacció).

Com hem pogut apreciar, el treball amb sensors i dades no és tan atractiu pels alumnes com altres recursos TAC ja que presenta certes dificultats. Per això, pot ajudar-hi que aquestes feines de captura de dades tinguin un objectiu clar que ajudi a solucionar una situació rellevant i propera als alumnes $i$ així tinguin sentit i estiguin justificades les operacions que fem, per exemple veure com puja la temperatura de la massa de pa quan fermenta (fig. 8).

Els alumnes estan més acostumats a mesurar la temperatura en situacions quotidianes i això pot significar més facilitat per interpretar les dades relacionades amb la temperatura que no pas amb el so i la llum.

En l'àmbit metodològic s'ha observat que quan es descarrega la consola de sensors és important analitzar les dades per variables separades: temperatura, il-luminació i so, perquè sinó són massa dades juntes $i$ en aquests nivells costa d'interpretar-ne tantes.

Tenint en compte que aquests alumnes de quart era la primera vegada que manipulaven i interpreta-

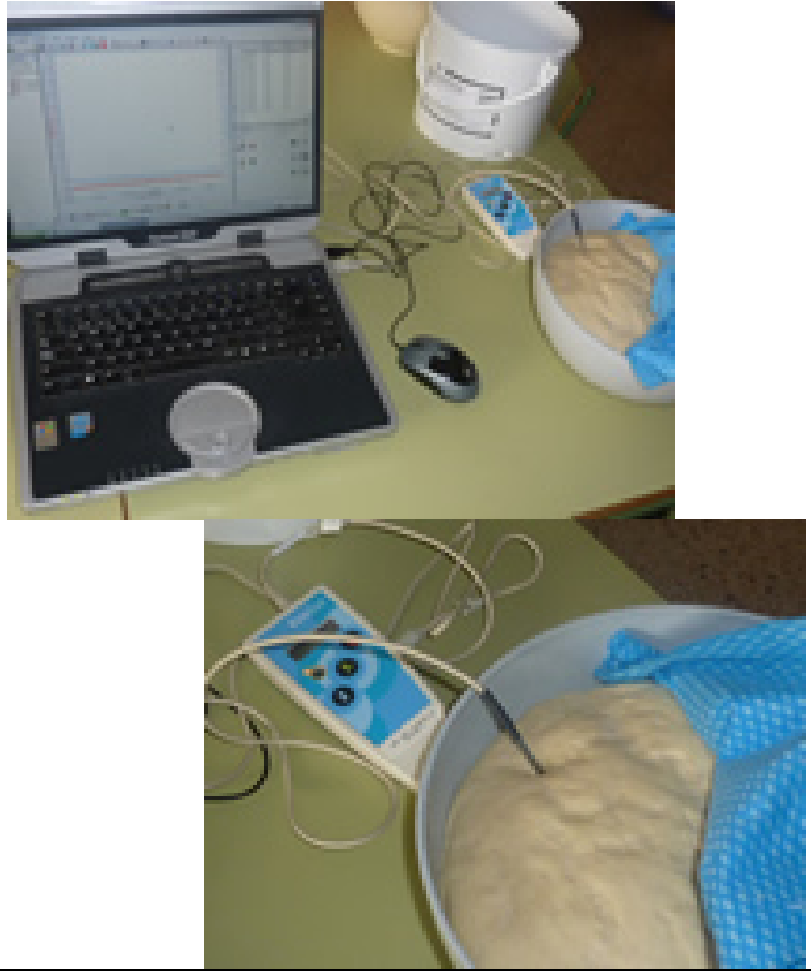

Figura 8. Control de temperatura de la massa de pa mentre reposa. Alumnes de 5è., escola Sant Josep - El Pi.

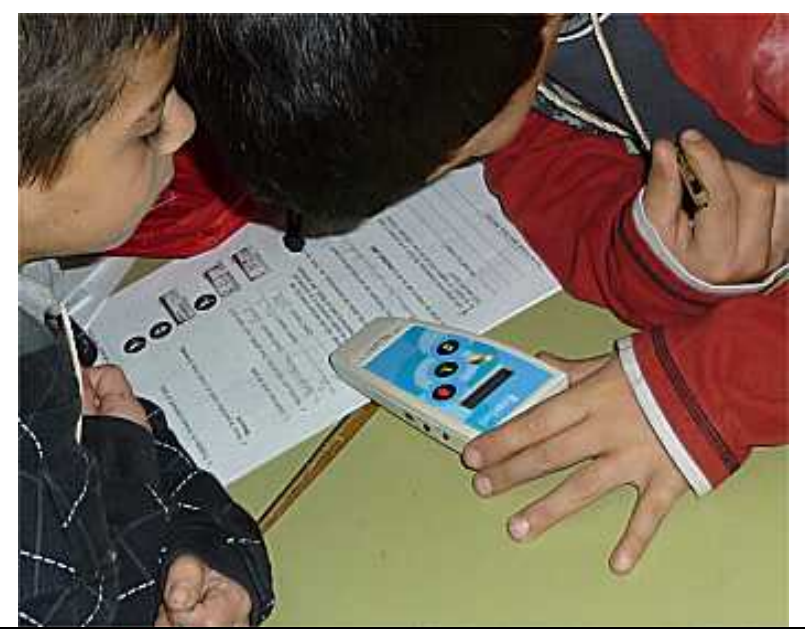

Figura 9. Alumnes fent ús de la consola de sensors i consulta de dades de forma directa. Escola Joan Maragall.

ven dades d'una taula, que feien gràfics i que treballaven amb aparells de mesura "més sofisticats", s'ha de valorar l'esforç que han fet per entendre els resultats obtinguts. Caldria continuar el treball de captura de dades i la seva interpretació en diferents situacions contextualitzades $\mathrm{i}$ properes per aconseguir dominar millor les representacions gràfiques 
de diferents tipus que ajudarien a la comprensió dels resultats obtinguts.

Pel que fa a l'avaluació de la UD hem de dir que totes aquestes activitats (presentació, exposició de la feina, activitat de síntesi sobre els sensors, qüestionari, participació activa al bloc...) en formen part.

\section{Pensar, fer i parlar sobre les plantes amb el suport de la consola de sensors}

Les accions o procediments que fan els alumnes dins del procés reconstructiu de pensar, experimentar i parlar en aquest projecte de treball sobre les plantes amb el suport de la consola de sensors Ecodad és molt variat i ho podem considerar beneficiós en el procés d'aprenentatge ja que permeten:

\section{- Pensar:}

analitzar situacions reals, identificar característiques ambientals de l'entorn, fer prediccions, adonar-se de les interaccions, trobar relacions amb el temps cronològic, predir i deduir, interpretar les dades, extrapolar a altres situacions entre ells i el seu entorn.

\section{- Experimentar o fer:}

manipular les consoles, obtenir dades amb programació i descàrrega de dades, interactuar amb altres TAC relacionades amb la consola (ordinador amb programaris i PDI), identificar detalls determinants en les gràfiques, comprovar els beneficis per a les plantes, fer observacions i anotacions periòdiques, comparar i mesurar diferents ritmes de creixement, fotografiar situacions concretes, fer un manteniment, solucionar problemes imprevistos, relacionar dades de les taules amb els gràfics.

\section{- Parlar o comunicar:}

planificar amb els fulls d'orientació, exposar les dades en funció de les variables, fer comentaris, converses i argumentacions sobre les dades, utilitzar taules i gràfics per mostrar resultats, compartir idees o no amb els companys durant el procés d'experimentació, documentar amb fotografies les dades i situacions, presentar i justificar en públic les seves conclusions.

\section{I per acabar}

En aquests tipus d'activitats i treball s'ha pogut comprovar de quina manera l'ús de les TAC poden afavorir l'alumnat en els seus processos cognitius a l'hora d'aprendre, és a dir, com les TAC els ajuden a fer evolucionar les seves idees inicials sobre diferents aspectes del nostre entorn. Per facilitar-lo, cal ensenyar l'alumnat a utilitzar de manera adient aquests recursos amb la finalitat que els permetin ser més autònoms i competents davant de situacions properes cercant solucions a problemes, plantejant preguntes, trobant evidències, interpretant dades, traient conclusions i comunicant-les.

Treballar amb instruments recol-lectors de dades, com és el cas de la consola de sensors, és molt interessant per ajudar els nens i nenes a prendre consciència que vivim en un món de canvis constants i que cal conèixer-los per descobrir les possibles interaccions amb tot allò que ens envolta.

\section{Bibliografia}

CESIRE - CDEC. Centre de Documentació i Experimentació en Ciències

http://www.xtec.es/cdec/ [Consulta: 7-11-2010]

CHIVITE, J. (2010) Com les TAC faciliten el pensar, l'experimentar $i$ el parlar de ciències a primària. Llicència d'estudis.

http://phobos.xtec.cat/sgfprp/resum.php?codi=2 039 [Consulta: 7-11-2010].

http://bloctaciencies.blogspot.com/ [Consulta: 7 11 - 2010].

LACASA, N., CHIVITE, J. i PADERN, M. (2009) Conversar utilitzant sensors. Perpectiva Escolar 331. pp 37-44.

MÀRQUEZ, C. i ROCA, M. (2004) Parlar i escriure sobre el que fem en el laboratori. La Talaia, 15, Revista digital. ISSN: 1579-9220.

Aquest article es basa en experiències realitzades en diferents centres durant el curs 20092010 i portades a terme gràcies a una llicència d'estudis retribuïda concedida pel Departament d'Educació de la Generalitat de Catalunya (Resolució EDU / 2413 / 2009, de 27 de juliol, DOGC núm. 54619 / 009 / 2009). 